\title{
A Novel in Vivo Model for Assessing the Impact of Geophagic Earth on Iron Status
}

\author{
Gretchen L. Seim ${ }^{1}$, Elad Tako ${ }^{2}$, Cedric Ahn ${ }^{3}$, Raymond P. Glahn ${ }^{2}$ and Sera L. Young ${ }^{4,5, *}$ \\ 1 Division of Nutritional Sciences, Cornell University, Ithaca, NY 14853, USA; gs373@cornell.edu \\ 2 USDA-ARS, Robert W. Holley Center for Agriculture and Health, Ithaca, NY 14853, USA; \\ et79@cornell.edu (E.T.); Raymond.Glahn@ars.usda.gov (R.P.G.) \\ 3 Department of Food Science, Cornell University, Ithaca, NY 14853, USA; cahn954@gmail.com \\ 4 Department of Population Medicine, Cornell University, Ithaca, NY 14853, USA \\ 5 Department of Anthropology, Northwestern University, Evanston, IL 60208, USA \\ * Correspondence: sera.young@cornell.edu; Tel.: +1-847-491-5402
}

Received: 4 May 2016; Accepted: 2 June 2016; Published: 13 June 2016

\begin{abstract}
The causes and consequences of geophagy, the craving and consumption of earth, remain enigmatic, despite its recognition as a behavior with public health implications. Iron deficiency has been proposed as both a cause and consequence of geophagy, but methodological limitations have precluded a decisive investigation into this relationship. Here we present a novel in vivo model for assessing the impact of geophagic earth on iron status: Gallus gallus (broiler chicken). For four weeks, animals were gavaged daily with varying dosages of geophagic material or pure clay mineral. Differences in haemoglobin $(\mathrm{Hb})$ across treatment groups were assessed weekly and differences in liver ferritin, liver iron, and gene expression of the iron transporters divalent metal transporter 1 (DMT1), duodenal cytochrome B (DcytB) and ferroportin were assessed at the end of the study. Minimal impact on iron status indicators was observed in all non-control groups, suggesting dosing of geophagic materials may need refining in future studies. However, this model shows clear advantages over prior methods used both in vitro and in humans, and represents an important step in explaining the public health impact of geophagy on iron status.
\end{abstract}

Keywords: geophagy; iron absorption; intestine; broiler chicken; anaemia; pica; clay

\section{Introduction}

Geophagy, the intentional ingestion of earth, is practiced in many cultures on all inhabited continents [1-3]. Despite widespread consumption and documented potential for both positive and negative health consequences, the etiology and consequences of geophagy remain unclear [4]. Geophagy has been frequently associated with anemia, especially iron (Fe) deficiency anemia. Anemia remains a significant global health concern. As much as $8.8 \%$ of the total disability from all conditions in 2010 was attributed to anemia, the most common etiology being Fe deficiency [5]. Pooled analysis of the relationship between geophagy and anemia revealed that geophagy is significantly associated with lower blood hemoglobin $(\mathrm{Hb})$ levels (weighted mean difference $=-0.95 \mathrm{~g} / \mathrm{dL}$ ) and individuals with geophagy were two times more likely to be anemic [6]. Because of this relationship, the majority of explanations about the causes and consequences of geophagy involve Fe [3,7-14]. One explanation holds that geophagy is an adaptive response to Fe deficiency, i.e., it is a means to increase Fe intake [15-17]. Another is that geophagy is a non-adaptive response to Fe deficiency; altered brain function has been speculated to cause cravings for earth and other non-food items [18]. The causality has also been posited in the opposite direction: geophagy may cause Fe deficiency by inhibiting its absorption $[3,9]$. This may occur through dietary Fe being adsorbed by the earth in the alimentary canal or by earth binding to the mucin layer of the intestine, creating a physical barrier to Fe absorption [19-22]. 
A number of studies have attempted to elucidate the relationship between Fe status and geophagy through in vitro analysis of geophagic substances. Data on total elemental composition (TEC) have been the focus of the majority of the analyses of geophagic earth performed to date [7,15,23-25]. Most of these studies have reported high concentrations of Fe in geophagic earth relative to concentrations found in food, leading the authors to conclude that geophagy is a source of Fe. Yet TEC does not account for bioavailability, which is known to be highly variable depending on the chemical form of the Fe and other factors [26]. A smaller number of in vitro studies have taken bioaccessiblity (the fraction of a mineral element that is soluble in the gastrointestinal environment and available for absorption [27]) or bioavailability (the proportion of an ingested mineral element that is absorbed and either utilized in a metabolic pathway or sequestered in body stores [28]) into account. Most [20,29-31] but not all [32] found little bioaccessible Fe. Three in vitro studies to date have also investigated the potential ability of geophagic earth to adsorb Fe from a food source or Fe in solution, thereby making it unavailable for absorption. These studies concluded that some, but not all, geophagic earth samples were able to significantly adsorb bioavailable Fe, i.e., they have the potential to reduce Fe absorption $[20,33,34]$.

Although these in vitro studies provide valuable information about the potential of geophagic substances to affect Fe absorption, alone they cannot definitively answer questions about causality. In vivo experiments offer a far better approximation of how geophagic earth impacts Fe absorption, in part because they are able to better capture the interaction of geophagic substances with the mucin layer as well as interactions with other ingesta. In vivo studies have actually been conducted in humans with Turkish [19,21,35], Texan [36], and South African [22] geophagic earths and found that geophagy does not increase Fe status and may even decrease it. However, these experiments were done more than 30 years ago and have a number of limitations, including outdated methods, very small sample sizes, and inadequate statistical analysis [9]. Furthermore, the mechanisms by which geophagic substances inhibit Fe absorption as well as the magnitude of the effect on Fe status remain unclear.

Given the limited in vivo data about the influence of geophagy on Fe absorption, our objectives were two-fold. The first was to develop an in vivo model that would permit the rigorous assessment of the capacity of geophagic earth and clay minerals to influence Fe status. We selected Gallus gallus (broiler chicken) as a model, which has been demonstrated to be a useful and sensitive method to test Fe bioavailability from a variety of Fe sources [37,38]. Our second objective was to test the effects of geophagic earth and clay minerals on a range of markers of Fe status. This included blood hemoglobin $(\mathrm{Hb})$ concentration, liver ferritin and liver Fe concentrations, all of which decrease in response to dietary Fe deficiency. Additionally we measured duodenal expression of genes related to Fe absorption (divalent metal transporter 1 (DMT1), ferroportin, and duodenal cytochrome B (DcytB)) which have been shown to increase in response to Fe deficiency. All of these Fe status markers have been shown to be appropriately sensitive to iron status in the broiler chicken model $[37,38]$.

\section{Materials and Methods}

\subsection{Animals and Diets}

One hundred and twenty Cornish cross fertile broiler eggs were obtained from a commercial hatchery (Moyer's chicks, Quakertown, PA, USA). The eggs were incubated in the Cornell University Animal Science poultry farm incubator. After hatching, chicks were housed in a total-confinement building (three chicks per $1 \mathrm{~m}^{2}$ metal cage) under controlled temperatures. The chicks were exposed to $16 \mathrm{~h}$ of light daily. Chicks were given ad libitum access to water throughout the study and ad libitum access to the experimental diet (Table 1) during the day; feed was taken away at night and replaced each morning after gavaging. The experimental diet was formulated to be marginally adequate in Fe so that Fe status would be more sensitive to different Fe intakes. All animal protocols were approved by the Cornell University Institutional Animal Care and Use Committee (Ethic approval code: 2007-0129). 
Table 1. Composition of Fe-inadequate experimental diet.

\begin{tabular}{cc}
\hline Ingredient & (g/kg Diet) \\
\hline Ground yellow corn & 750 \\
Dry skim milk & 100 \\
DL-Methionine & 2.5 \\
Vegetable oil & 30 \\
Corn starch & 46.5 \\
Choline chloride $^{\text {a }}$ & 0.75 \\
Vitamin premix $^{\text {a }}$ & 10 \\
Mineral premix $^{\text {a }}$ & 60 \\
Ferric citrate $^{\mathrm{b}}$ & 0.25 \\
Total & 1000
\end{tabular}

\begin{abstract}
a Vitamin-mineral premix provided per $\mathrm{kg}$ of diet: retinyl palmitate, $1208 \mu \mathrm{g}$; ergocalicferol, $5.5 \mu \mathrm{g}$; DL- $\alpha$-tocopheryl acetate, $10.72 \mathrm{mg}$; menadione, $0.5 \mathrm{mg}$; D-biotin, $0.05 \mathrm{mg}$; choline chloride, $0.5 \mathrm{~g}$; folic acid, $0.3 \mathrm{mg}$; niacin, $15 \mathrm{mg}$; Ca-D pantothenate, $10 \mathrm{mg}$; riboflavin, $3.5 \mathrm{mg}$; thiamin, $1 \mathrm{mg}$; pyridoxine, $1.5 \mathrm{mg}$; cyanocobalamin, $17.5 \mu \mathrm{g} ; \mathrm{CuSO}_{4} * 5 \mathrm{H}_{2} \mathrm{O}, 6 \mathrm{mg} ; \mathrm{C}_{2} \mathrm{H}_{8} \mathrm{~N}_{2} * 2 \mathrm{HI}, 0.14 \mathrm{mg} ; \mathrm{MnO}, 4 \mathrm{mg} ; \mathrm{Na}_{2} \mathrm{SeO}_{3}, 0.3 \mathrm{mg}$; and $\mathrm{ZnO}$, $100 \mathrm{mg} ;{ }^{\text {b }}$ Ferric citrate was marginally lower than NRC recommendations so that Fe status of birds would be more sensitive to different Fe intakes.
\end{abstract}

The geophagic earth used in this study, which has been previously characterized by Seim et al. [34], came from a market in Tororo, Uganda, and had been identified to be commonly eaten by pregnant participants in an ongoing clinical study (NCT00993031) [39]. Participants reported consuming approximately $70 \mathrm{~g}$ per day, slightly higher than the $30 \mathrm{~g} /$ day modal amount reported elsewhere in the literature [40]. The pure clay mineral smectite (STx-1b, Clay Minerals Society) was selected because it is one of the clay minerals that are most commonly found in high proportion in geophagic earths [40], such that its impact on Fe absorption would be highly relevant. The Fe content of the geophagic earth and smectite, as determined by inductively coupled plasma atomic emission spectroscopy (ICP-AES), are 17,475 ppm and $4795 \mathrm{ppm}$, respectively [34].

The quantity of clay minerals and geophagic earth administered to the chickens was determined based on quantities typically consumed by humans, reported previously [9]. The mean amount of this particular type of geophagic earth consumed daily $(\sim 70 \mathrm{~g})$ was converted to a ratio of earth to average body weight of a typical human $(\sim 70 \mathrm{~kg}$, or 1:1000). This ratio was then applied to the estimated mean body weight of the chicks to calculate earth/clay doses (Table 2). The earth/clay dose was increased weekly based on the estimated mean body weight of the chicks. To account for the varying levels of clay minerals found in geophagic earth $[9,15,26]$ three treatment groups were designed using the smectite. The amount of smectite gavaged daily was $20 \%, 35 \%$ and $50 \%$ of the amount of geophagic earth gavaged (group 5) in groups 2, 3 and 4, respectively.

Table 2. Dosage of clay minerals and geophagic earth, by treatment group and week of experiment.

\begin{tabular}{|c|c|c|c|c|c|c|}
\hline \multirow{2}{*}{\multicolumn{2}{|c|}{ Treatment Group }} & \multicolumn{5}{|c|}{$\begin{array}{l}\text { Dosages g of Clay Minerals or Geophagic Earth Gavaged/Day } \\
\text { (mg Fe Content) }\end{array}$} \\
\hline & & $1(n=12)$ & $2(n=12)$ & $3(n=12)$ & $4(n=12)$ & $5(n=12)$ \\
\hline Week & $\begin{array}{l}\text { Predicted Mean } \\
\text { Chicken Mass (kg) }\end{array}$ & Control $^{a}$ & $\begin{array}{l}\text { "Low" } \\
\text { Smectite }\end{array}$ & $\begin{array}{l}\text { "Medium" } \\
\text { Smectite }\end{array}$ & $\begin{array}{l}\text { "High" } \\
\text { Smectite }\end{array}$ & $\begin{array}{l}\text { Geophagic } \\
\text { Earth }\end{array}$ \\
\hline 1 & 0.20 & 0 & $0.04(19)$ & $0.07(34)$ & $0.10(48)$ & $0.20(3.50)$ \\
\hline 2 & 0.30 & 0 & $0.06(29)$ & $0.10(48)$ & $0.15(72)$ & $0.30(5.24)$ \\
\hline 3 & 0.30 & 0 & $0.06(29)$ & $0.10(48)$ & $0.15(72)$ & $0.30(5.24)$ \\
\hline 4 & 0.35 & 0 & $0.07(34)$ & $0.12(58)$ & $0.17(82)$ & $0.35(6.12)$ \\
\hline
\end{tabular}




\subsection{Study Design and Assessments}

At week 4, after hatching, chicks were randomized into five treatment groups (on the basis of body weight, gender and blood $\mathrm{Hb}$ concentration) to ensure equal allocation between treatment groups $(n=12)$. Treatment groups were gavaged with varying doses of geophagic earth and smectite clay mineral samples daily for four weeks (Table 2). Gavaging was performed on all birds each morning before they were exposed to food. The earth and clay samples were suspended in water, and oil was applied to the pipettors before gavaging. Treatment group 1 was treated as a control and was gavaged daily with water. At the end of four weeks, birds were euthanized using carbon dioxide. Sections of the duodenum and liver were removed and immediately frozen in liquid nitrogen then stored in a $-80{ }^{\circ} \mathrm{C}$ freezer until analysis.

Body weight and $\mathrm{Hb}$ were measured weekly. Ten birds per treatment group were randomly sampled each week for $\mathrm{Hb}$ analysis. Blood samples were collected from the wing vein $(\sim 100 \mu \mathrm{L})$ using micro-hematocrit heparinized capillary tubes (Fisher, Pittsburgh, PA, USA). Blood Hb concentrations were determined using the cyanmethemoglobin method (H7506-STD, Pointe Scientific Inc., Canton, MI, USA).

\subsubsection{Isolation of Total RNA}

RNA extraction was performed from $30 \mathrm{mg}$ of the distal duodenal tissue on six randomly selected birds per treatment group using a Qiagen RNeasy Mini Kit (Qiangen Inc., Valencia, CA, USA), according to the manufacturer's protocol and as previously described [38].

\subsubsection{DMT-1, DcytB and Ferroportin Gene Expression Analysis}

As previously described [37,38,41], PCR was carried out with primers chosen from the fragment of the chicken (Gallus gallus) duodenal DMT1 gene (GeneBank datatbase; GI 206597489), DcytB gene (GI 20380692) and Ferroportin gene (GI 61098365). Ribosomal 18S was used to normalize the results, with primers from the Gallus gallus $18 \mathrm{~S}$ ribosomal RNA (GI 7262899).

All PCR products were separated by electrophoresis on $2 \%$ agarose gel, stained with ethidium bromide, and quantified using the Quantity-One 1-D analysis program (Bio-Rad, Hercules, CA, USA).

\subsubsection{Liver Ferritin and Fe}

Four randomly selected liver samples per treatment group were treated as described elsewhere [37,42]. Briefly, the frozen tissue samples were thawed on ice for approximately $30 \mathrm{~min}$. One gram of sample was diluted into $1 \mathrm{~mL}$ of $50 \mathrm{mM}$ Hepes buffer, $\mathrm{pH} 7.4$, and homogenized on ice at $5000 \mathrm{~g}$ for $2 \mathrm{~min}$. One $\mathrm{mL}$ of each homogenate was subjected to heat treatment for $10 \mathrm{~min}$ at $75^{\circ} \mathrm{C}$ to aid isolation of ferritin since other proteins are not stable at that temperature [42,43]. After heat treatment, the samples were immediately placed on ice for $30 \mathrm{~min}$. Thereafter, samples were centrifuged at 13,000 $\mathrm{g}$ for $30 \mathrm{~min}$ at $4{ }^{\circ} \mathrm{C}$ until a clear supernatant was obtained and the pellet containing most of the insoluble denaturated proteins was discarded. All tests were conducted in duplicate for each animal.

\subsubsection{Electrophoresis and Staining Gels}

Native polyacrylamide gel electrophoresis was conducted using a $6 \%$ separating gel and a $5 \%$ stacking gel. Samples were run at a constant voltage of $100 \mathrm{~V}$. After electrophoresis, the gels were treated with either of the two stains as described earlier [44]: Coomasie blue G-250 stain, specific for proteins, or potassium ferricyanide $\left(\mathrm{K}_{3} \mathrm{Fe}(\mathrm{CN})_{6}\right)$ stain, specific for Fe. The corresponding band found in the protein and Fe stained gel was considered to be ferritin.

The gels were scanned with Bio-Rad densitometer. Measurements of the bands were conducted using the Quantity-One 1-D analysis program (Bio-Rad, Hercules, CA, USA). The local background was subtracted from each sample. Horse spleen ferritin (Sigma Aldrich Co., St. Louis, MO, USA) was used as a standard for calibrating ferritin protein and Fe concentrations of the samples [37,38,42,43]. 


\subsection{Statistical Analysis}

One-way ANOVA tests were used to compare mean body weight, feed intake, Fe intake and Fe status indicators between or among treatment groups using JMP ${ }^{\circledR}$ Pro 10.0.0 (SAS Institute Inc., Cary, NC, USA). Post-hoc Tukey's honestly significantly different (HSD) tests were performed to make pairwise comparisons when ANOVA tests indicated significance. Statistical significance was defined as $p<0.05$.

\section{Results}

\subsection{Growth Rates, Feed Intakes, Fe Intakes and Hemoglobin $(\mathrm{Hb})$}

There were no significant differences in body weight or weekly cumulative feed intake by treatment group at any time (Table 3). Weekly cumulative Fe intake was significantly higher among birds gavaged with geophagic earth (Group 5) than all other treatment groups at every week $(p \leqslant 0.0001$, Table 3). Despite a two- to three-fold higher weekly Fe intake in Group 5, Hb concentrations were not significantly different among any of the groups at any time point (Table 3).

Table 3. Body weights, cumulative weekly feed intake, Fe intake, and $\mathrm{Hb}$ from day 0 to day 28 of experiment, by treatment group.

\begin{tabular}{|c|c|c|c|c|c|c|}
\hline & Treatment & Day 0 & Day 7 & Day 14 & Day 21 & Day 28 \\
\hline \multicolumn{7}{|c|}{ Body weight (g) ${ }^{1}$} \\
\hline 1 & Control & $210^{a}$ & $243.1^{\mathrm{a}}$ & $354.0^{\mathrm{a}}$ & $453.4^{\mathrm{a}}$ & $520.4^{\mathrm{a}}$ \\
\hline 2 & Low Smectite & $209^{a}$ & $241.6^{\mathrm{a}}$ & $361.1^{\mathrm{a}}$ & $480.0^{\mathrm{a}}$ & $534.2^{\mathrm{a}}$ \\
\hline 3 & Medium Smectite & $210^{a}$ & $233.6^{\mathrm{a}}$ & $344.6^{\mathrm{a}}$ & $443.0^{\mathrm{a}}$ & $494.7^{\mathrm{a}}$ \\
\hline 4 & High Smectite & $210^{a}$ & $232.3^{a}$ & $342.2^{\mathrm{a}}$ & $419.8^{a}$ & $458.8^{a}$ \\
\hline 5 & Geophagic Earth & $211^{\mathrm{a}}$ & $250.8^{a}$ & $343.4^{\mathrm{a}}$ & $441.2^{\mathrm{a}}$ & $503.5^{\mathrm{a}}$ \\
\hline \multicolumn{7}{|c|}{ Feed intake (g/week/bird) ${ }^{1,2}$} \\
\hline 1 & Control & - & $203.4^{\mathrm{a}}$ & $293.9^{a}$ & $346.3^{a}$ & $438.8^{a}$ \\
\hline 2 & Low Smectite & - & $189.3^{\mathrm{a}}$ & $276.6^{a}$ & $362.9^{a}$ & $382.3^{a}$ \\
\hline 3 & Medium Smectite & - & $183.7^{\mathrm{a}}$ & $261.1^{\mathrm{a}}$ & $308.9^{a}$ & $392.3^{a}$ \\
\hline 4 & High Smectite & - & $183.2^{\mathrm{a}}$ & $268.7^{\mathrm{a}}$ & $324.9^{\mathrm{a}}$ & $361.8^{a}$ \\
\hline 5 & Geophagic Earth & - & $181.9^{a}$ & $279.9^{\mathrm{a}}$ & $307.4^{\mathrm{a}}$ & $380.2^{a}$ \\
\hline \multicolumn{7}{|c|}{ Fe intake (mg/week/bird) $1,2,3$} \\
\hline 1 & Control & - & $10.2^{a}$ & $14.7^{\mathrm{a}}$ & $17.3^{\mathrm{a}}$ & $21.9^{a}$ \\
\hline 2 & Low Smectite & - & $10.8^{\mathrm{a}}$ & $15.8^{a}$ & $20.1^{\mathrm{a}}$ & $21.4^{\mathrm{a}}$ \\
\hline 3 & Medium Smectite & - & $11.5^{\mathrm{a}}$ & $16.5^{\mathrm{a}}$ & $19.5^{\mathrm{a}}$ & $23.7^{\mathrm{a}}$ \\
\hline 4 & High Smectite & - & $12.4^{\mathrm{a}}$ & $18.1^{\mathrm{a}}$ & $20.9^{a}$ & $23.9^{a}$ \\
\hline 5 & Geophagic Earth & - & $33.6^{b}$ & $50.7^{b}$ & $52.1^{b}$ & $61.8^{b}$ \\
\hline \multicolumn{7}{|c|}{ Haemoglobin $(\mathrm{g} / \mathrm{dL})^{4}$} \\
\hline 1 & Control & $9.02^{a}$ & $8.48^{\mathrm{a}}$ & $8.37^{\mathrm{a}}$ & $8.30^{a}$ & $8.28^{a}$ \\
\hline 2 & Low Smectite & $9.02^{\mathrm{a}}$ & $8.55^{a}$ & $8.40^{\mathrm{a}}$ & $8.21^{a}$ & $8.16^{\mathrm{a}}$ \\
\hline 3 & Medium Smectite & $9.02^{\mathrm{a}}$ & $8.43^{\mathrm{a}}$ & $8.28^{a}$ & $8.25^{\mathrm{a}}$ & $8.18^{a}$ \\
\hline 4 & High Smectite & $9.02^{\mathrm{a}}$ & $8.42^{\mathrm{a}}$ & $8.24^{\mathrm{a}}$ & $8.20^{\mathrm{a}}$ & $8.18^{a}$ \\
\hline 5 & Geophagic Earth & $9.02^{\mathrm{a}}$ & $8.44^{\mathrm{a}}$ & $8.37^{\mathrm{a}}$ & $8.30^{\mathrm{a}}$ & $8.19^{a}$ \\
\hline
\end{tabular}

$\mathrm{a}, \mathrm{b}$ within a column, means without a common letter are significantly difference, $p<0.05$ (Tukey's honest significant difference (HSD)); ${ }^{1}$ Values are means, $n=12$, except where noted; ${ }^{2}$ Values are weekly feed $/ \mathrm{Fe}$ intakes for the seven days preceding the day designated in the column heading; ${ }^{3}$ Fe intakes were calculated by summing Fe derived from feed intake data (50 ppm) with Fe derived from dosed geophagic earth $(17,475 \mathrm{ppm})$ or mineral clay $(4795 \mathrm{ppm})$. Fe concentration of the geophagic earth and smectite were determined using inductively-coupled plasma atomic emission spectroscopy (ICP-AES); ${ }^{4}$ Values are means, $n=10$.

\subsection{Liver Ferritin and Fe}

Mean liver ferritin levels (expressed as relative to a standard of horse spleen ferritin as arbitrary units (AU)) differed significantly as a function of the treatment group, $F(4,15)=4.37, p=0.015$ (Figure 1). The geophagic group (Treatment group 5) had significantly higher mean liver ferritin 
$(M=1.295 \mathrm{AU})$ than treatment groups $1(M=1.128 \mathrm{AU})$ and $2(M=1.103 \mathrm{AU})$. No other comparisons were significant. Mean liver Fe concentration (ppm) did not differ significantly by treatment group.

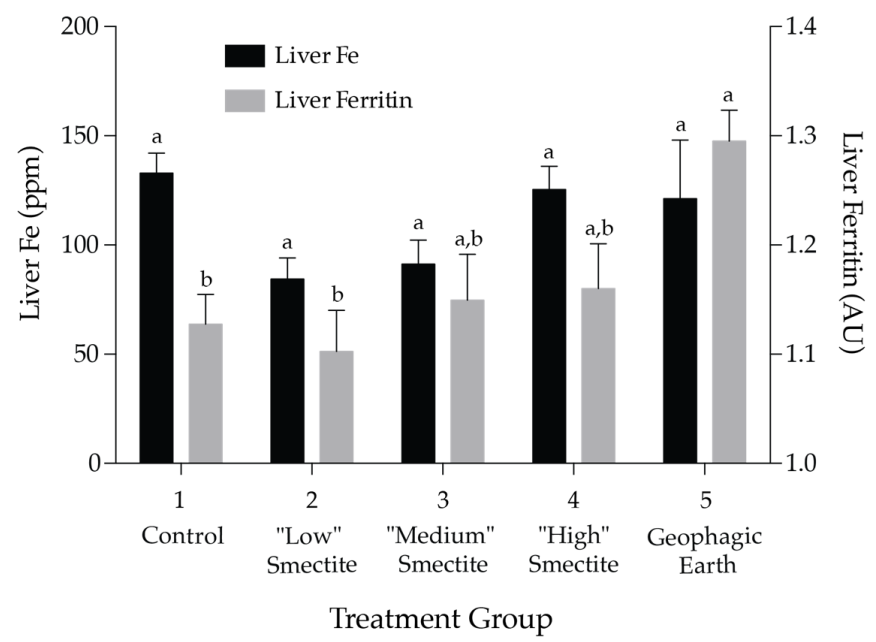

Figure 1. Liver ferritin and liver Fe at day 28. Ferritin levels are means $(n=4, \pm \mathrm{SEM})$ and are expressed relative to a standard of horse spleen ferritin as arbitrary units (AU). Liver Fe levels are means $(n=10 \pm \mathrm{SEM}$ ). Means without a common letter are significantly different at $p<0.05$ (Tukey's honest significant difference (HSD)).

\subsection{Gene Expression of Fe Transporters DMT-1, Ferroportin and DcytB in the Duodenum}

Gene expression analysis, with results reported relative to $18 \mathrm{~S}$ rRNA, indicated no significant differences between groups in expression of duodenal ferroportin. Relative expression of both DMT1 and DcytB differed significantly as a function of the treatment group (Figure 2, $F(4,20)=2.99, p=0.0435$ and $F(4,20)=3.89, p=0.017$, respectively). Treatment group $2(M=0.559 \mathrm{AU})$ had significantly higher relative DMT1 expression than treatment group $3(M=0.551 \mathrm{AU})$ and significantly lower relative DcytB expression $(M=0.464 \mathrm{AU})$ than treatment group $4(M=0.468 \mathrm{AU})$. Overall, treatment did not lead to biologically relevant alterations in transcript levels of duodenal transporters, suggesting that these treatments did not drastically alter the birds' iron status.

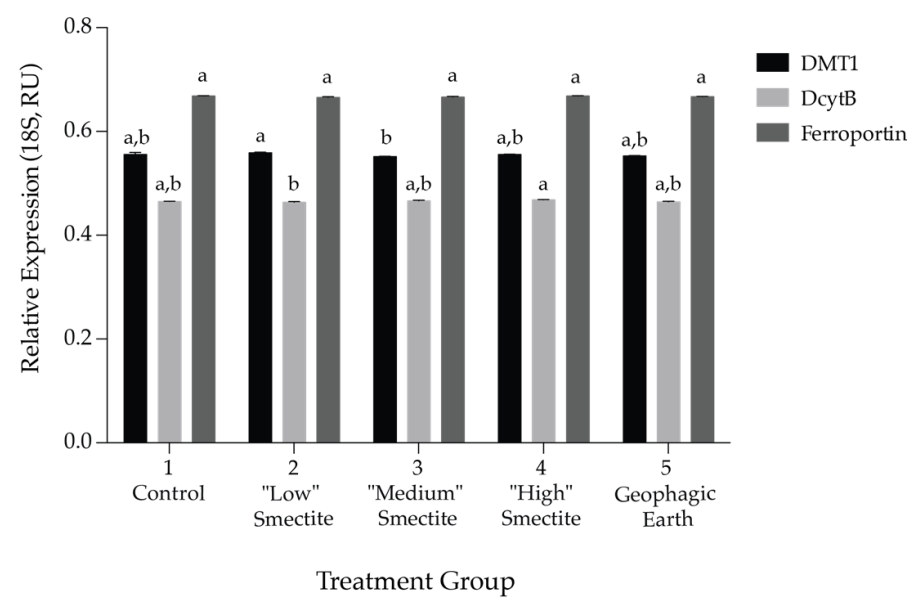

Figure 2. Chicken duodenal mRNA expression of divalent metal transporter 1 (DMT1), duodenal cytochrome B (DcytB), and ferroportin. Expression is shown relative to expression of 18S rRNA in arbitrary units (AU). Values are means $\pm \mathrm{SD}, n=5$. Means without a common letter are significantly different at $p<0.05$ (Tukey's HSD). 


\section{Discussion}

Our first objective was to identify and apply an in vivo methodology for studying the relationship between geophagy and Fe status. Gallus gallus has several advantages over previous in vitro models. These include a closer approximation of the digestive process; the presence of mucin and a regular interaction with the food matrix are particular advantages. It also is a fast-growing animal that is sensitive to dietary deficiencies of mineral elements such as Fe. As such, it holds potential as a relevant model and as a source of tissues for in vitro Fe bioavailability studies, in vivo feeding trials, or both. In addition, chickens are cheaper and easier to maintain than many other species. Moreover, the overall size of the adult broiler allows for repeated blood sampling at volumes suitable for measurement of mineral elements. The chicken model also offers advantages over previous in vivo work (done in humans) including the possibility of a more rigorous evaluation of Fe status and permitting greater control over geophagic earth dosing via oral gavage of the sample of interest.

Our second objective was to determine the effect of geophagic materials on Fe status, both in terms of their ability to provide bioavailable Fe and their ability to inhibit Fe absorption from other sources. In terms of providing bioavailable $\mathrm{Fe}$, although treatment group 5 received significantly higher amounts of elemental Fe than other groups, no significant difference was observed between $\mathrm{Hb}$, liver Fe concentration or expression of genes involved in Fe absorption and transportation. However, treatment group 5 did have significantly higher liver ferritin levels as compared to the control, indicating increased liver Fe stores in group 5; hence, some Fe in the geophagic earth was bioavailable. Differences in duodenal DMT1 and DcytB between treatment groups were minor, suggesting that all birds were Fe deficient (as expected due to marginal levels of Fe in the experimental diet) and therefore there was a gene expression upregulation to compensate for the lack of Fe in their diets. It also suggests that the treatment did not affect the tissue functionality (i.e., the gene expression) by increasing the dietary Fe bioavailability or increasing Fe content in the lumen (from the soil). These findings are consistent with in vitro experiments with smectite (STx-1b, Clay Minerals Society) and Ugandan geophagic earth using the Caco-2 model [34], which also found that when combined with a food source of Fe (cooked white beans), these samples do not provide significantly increased amounts of bioavailable Fe.

In terms of geophagic substances' ability to inhibit Fe absorption, we found no significant negative effects of geophagic earth/clay mineral consumption on Fe status. This indicates that these samples, when dosed at this level, do not have the ability to adsorb dietary Fe in amounts substantial enough to cause a reduction in Fe absorption. This is in striking contrast to previous in vitro and in vivo studies. Of the three in vitro studies to date that have investigated the ability of geophagic substances to bind to bioavailable Fe $[20,33,34]$, most but not all of the samples were shown to reduce bioavailable or bioaccessible Fe. Of the five in vivo studies in humans $[19,21,22,35,36]$, four concluded that the consumption of earth prior to the consumption of Fe had the ability to reduce the absorption of Fe.

Furthermore, our expectation of reduced Fe bioavailability was based on smectite's well-established adsorptive properties. Smectite clays have been found to bind well to a number of substances (e.g., herbicides [45], tannic acid [46], T-2 toxin [47] and aflatoxins [48]), an adsorptive capacity often attributed to its high cation exchange capacity (CEC). Because of its high CEC and adsorptive capacity, it has been suggested as integral to the ability of geophagic earths to bind Fe [20]. Oral diosmectite has also been found to interact with mucus molecules to strengthen the mucosal barrier in the gastrointestinal tract $[47,49]$ which could potentiate the negative effect of smectite on dietary Fe absorption.

Overall, the consumption of the clay mineral smectite and geophagic earth at concentrations in this study resulted in minimal impact on Fe status. We hypothesize that the most likely explanation for the absence of observed effect on Fe status is inadequate dosing of both smectite and geophagic earth. Our calculations for clay and earth dosing were based on a ratio of geophagic earth to body weight in humans. However, in order to investigate the interaction between the geophagic earth and the Fe in the food, it might have been more appropriate to calculate dosing based on the ratio of daily food consumption to daily geophagic earth. This ratio would result in much larger doses of geophagic 
earth and clay minerals treatments ( 1-7 g/day). Alternatively, it may have been more appropriate to calculate dosages based on the relative length of alimentary canal (human: $\sim 5.5-7 \mathrm{~m}$; chicken: $\sim 2 \mathrm{~m}$ ) in order to accurately capture the effect of the interaction of geophagic soil or mineral clay with the intestinal brush border. This logic would also result in a much larger dose of geophagic earth and clay mineral ( 5-25 g/day).

This study has several additional limitations. The human diet is much more diverse than that fed to these animals, and typically includes both heme and non-heme $\mathrm{Fe}$, such that interactions between geophagic earth and dietary Fe may be more complex that what is modeled with a simple corn-based diet. Further, chickens received earth or clay minerals only once per day and after a night of fasting, but humans have reported consuming earth sometimes multiple times a day and both before and after meals. The resources and expertise needed for animal experimentation must be weighed carefully when considering in vitro vs. in vivo approaches.

\section{Conclusions}

In summary, Gallus gallus represents a significant advance over previous methods for studying the effects of geophagy on Fe status. This versatile model allows not only the investigation of the elemental and bioavailable Fe content but also permits the determination of any inhibitory effects on dietary Fe absorption in a relatively simple and cost-effective way. As such, the use of this model with geophagic and other pica substances will likely lead to important clarifications about the health consequences of geophagy, a nutritional enigma of real public health concern.

Acknowledgments: We gratefully acknowledge Mary Bodis at the USDA-ARS, Robert W. Holley Center for Agriculture and Health for her excellent technical support.

Author Contributions: S.L.Y., G.S., E.T., and R.G. conceived and designed the experiments, G.S., E.T., and C.A. performed the experiments, E.T., S.L.Y. and G.S. analyzed the data, and S.L.Y. and G.S. wrote the paper. All authors critically reviewed the final draft.

Conflicts of Interest: The authors declare no conflict of interest.

\section{Abbreviations}

The following abbreviations are used in this manuscript:

$\mathrm{Fe} \quad$ iron

$\mathrm{Hb} \quad$ hemoglobin

TEC total elemental composition

DMT1 divalent metal transporter 1

DcytB duodenal cytochrome B

CEC cation exchange capacity

GI gastrointestinal

ICP-AES inductively-coupled plasma atomic emission spectroscopy

\section{References}

1. Arnell, B.; Lagercrantz, S. Geophagical Customs; Humanistiska Fonden: Uppsala, Sweden, 1958.

2. Laufer, B. Geophagy; Field Museum of Natural History: Chicago, IL, USA, 1930.

3. Young, S.; Sherman, P.; Lucks, J.; Pelto, G. Why on earth? Evaluating hypotheses about the physiological functions of human geophagy. Q. Rev. Biol. 2011, 86, 97-120. [CrossRef] [PubMed]

4. Young, S.; Wilson, M.; Hillier, S.; Delbos, E. Differences and commonalities in physical, chemical and mineralogical properties of Zanzibari geophagic soils. J. Chem. Biol. 2010, 36, 129-140. [CrossRef] [PubMed]

5. Kassebaum, N.J.; Jasrasaria, R.; Naghavi, M.; Wulf, S.K.; Johns, N.; Lozano, R.; Regan, M.; Weatherall, D.; Chou, D.P.; Eisele, T.P. A systematic analysis of global anemia burden from 1990 to 2010. Blood 2014, 123, 615-624. [CrossRef] [PubMed]

6. Miao, D.; Young, S.; Golden, C. A meta-analysis of pica and micronutrient status. Am. J. Hum. Biol. 2015, 27, 84-93. [CrossRef] [PubMed]

7. Geissler, P.; Shulman, C.; Prince, R. Geophagy, iron status and anemia among pregnant women on the coast of Kenya. Trans. R. Soc. Trop. Med. Hyg. 1998, 92, 549-543. [CrossRef] 
8. Thomson, J. Anemia in pregnant women in eastern Caprivi, Namibia. S. Afr. Med. 1997, 87, 1544-1547.

9. Young, S. Pica in pregnancy: New ideas about an old condition. Annu. Rev. Nutr. 2010, 30, 403-422. [CrossRef] [PubMed]

10. Adam, I.; Khamis, A.; Elbashir, M. Prevalence and risk factors for anemia in pregnant women of eastern Sudan. Trans. R. Soc. Trop. Med. Hyg. 2005, 99, 739-743. [CrossRef] [PubMed]

11. Kawai, K.; Saathoff, E.; Antelman, G.; Msamanga, G. Geophagy (soil-eating) in relation to anemia and helminth infection among HIV-infected pregnant women in Tanzania. Am. J. Trop. Med. Hyg. 2009, 80, 36-43. [PubMed]

12. Malenganisho, W.; Magnussen, P. Intake of alcoholic beverages is a predictor of iron status and hemoglobin in adult Tanzanians. J. Nutr. 2007, 137, 2140-2146. [PubMed]

13. Antelman, G.; Msamanga, G.I.; Spiegelman, D. Nutritional factors and infectious disease contribute to anemia among pregnant women with human immunodeficiency virus in Tanzania. J. Nutr. 2000, 130, 1950-1957. [PubMed]

14. Tayie, F.; Lartey, A. Pica practice among pregnant Ghanaians: Relationship with infant birth-weight and maternal haemoglobin level. Ghana Med. J. 1999, 33, 67-76.

15. Aufreiter, S.; Hancock, R.; Mahaney, W. Geochemistry and mineralogy of soils eaten by humans. Int. J. Food Sci. Nutr. 1997, 48, 293-305. [CrossRef]

16. Hunter, J. Geophagy in Africa and in the United States: A Culture-Nutrition Hypothesis. Geogr. Rev. 1973, 63, 170-195. [CrossRef]

17. Mahaney, W.; Bezada, M.; Hancock, R. Geophagy of Holstein hybrid cattle in the northern Andes, Venezuela. Mt. Res. Dev. 1996, 16, 177-180. [CrossRef]

18. Youdim, M.; Iancu, T. Pica hypothesis. Br. J. Haematol. 1977, 36, 298. [CrossRef] [PubMed]

19. Çavdar, A.; Arcasoy, A. Hematologic and biochemical studies of Turkish children with pica a presumptive explanation for the syndrome of geophagia, iron deficiency anemia, hepatosplenomegaly and hypogonadism. Clin. Pediatr. 1972, 11, 215-223. [CrossRef]

20. Hooda, P.; Henry, C.; Seyoum, T. The potential impact of soil ingestion on human mineral nutrition. Sci. Total Environ. 2004, 333, 75-87. [CrossRef] [PubMed]

21. Minnich, V.; Okcuoglu, A.; Tarcon, Y. Pica in Turkey II. Effect of clay upon iron absorption. Am. J. Clin. Nutr. 1968, 21, 78-86. [PubMed]

22. Sayers, G.; Lipschitz, D.; Sayers, M. Relationship between pica and iron nutrition in Johannesburg Black adults. S. Afr. Med. J. 1974, 48, 1655-1660. [PubMed]

23. Abrahams, P. Geophagy (soil consumption) and iron supplementation in uganda. Trop. Med. Int. Health 1997, 2, 617-623. [CrossRef] [PubMed]

24. Abrahams, P.; Parsons, J. Geophagy in the tropics: An appraisal of three geophagical materials. Environ. Geochem. Health 1997, 19. [CrossRef]

25. Hunter, J.; DeKleine, R. Geophagy in Central America. Geogr. Rev. 1984, 74, 157-169. [CrossRef] [PubMed]

26. Wilson, M. Clay mineralogical and related characteristics of geophagic materials. J. Chem. Ecol. 2003, 29, 1525-1547. [CrossRef] [PubMed]

27. Benito, P.; Miller, D. Iron absorption and bioavailability: An updated review. Nutr. Res. 1998, 18, 581-603. [CrossRef]

28. Ruby, M.; Davis, A.; Schoof, R.; Eberle, S. Estimation of lead and arsenic bioavailability using a physiologically based extraction test. Environ. Sci. Technol. 1996, 30, 422-430. [CrossRef]

29. Dreyer, M.; Chaushev, P. Biochemical investigations in geophagia. J. R. Soc. Med. 2004, 97, 48. [CrossRef] [PubMed]

30. Kikouama, J.; Cornec, F.; Bouttier, S. Evaluation of trace elements released by edible clays in physicochemically simulated physiological media. Int. J. Food Sci. Nutr. 2009, 60, 130-142. [CrossRef] [PubMed]

31. Smith, B.; Rawlins, B.; Cordeiro, M. The bioaccessibility of essential and potentially toxic trace elements in tropical soils from Mukono District, uganda. J. Geol. Soc. Lond. 2000, 157, 885-891. [CrossRef]

32. Abrahams, P.; Follansbee, M.; Hunt, A.; Smith, B. Iron nutrition and possible lead toxicity: An appraisal of geophagy undertaken by pregnant women of UK Asian communities. Appl. Geochem. 2006, 21, 98-108. [CrossRef] 
33. Pebsworth, P.; Seim, G.; Huffman, M. Soil consumed by Chacma baboons is low in bioavailable iron and high in clay. J. Chem. Ecol. 2013, 39, 447-449. [CrossRef] [PubMed]

34. Seim, G.; Ahn, C.; Bodis, M.; Luwedde, F.; Miller, D. Bioavailability of iron in geophagic earths and clay minerals, and their effect on dietary iron absorption using an in vitro digestion/Caco-2 cell model. Food Funct. 2013, 4, 1263-1270. [CrossRef] [PubMed]

35. Arcasoy, A.; Cavdar, A.O.; Babacan, E. Decreased iron and zinc absorption in Turkish children with iron deficiency and geophagia. Acta Haematol. 1978, 60, 76-84. [CrossRef] [PubMed]

36. Talkington, K.; Gant, N.F., Jr.; Scott, D. Effect of ingestion of starch and some clays on iron absorption. Am. J. Obstet. Gynecol. 1970, 108, 262-267. [CrossRef]

37. Tako, E.; Blair, M.; Glahn, R. Biofortified red mottled beans (Phaseolus vulgaris L.) in a maize and bean diet provide more bioavailable iron than standard red mottled beans: Studies in poultry (Gallus gallus) and an in vitro digestion/Caco-2 model. Nutr. J. 2011, 10, 113. [CrossRef] [PubMed]

38. Tako, E.; Glahn, R. White beans provide more bioavailable iron than red beans: studies in poultry (Gallus gallus) and an in vitro digestion/Caco-2 model. Int. J. Vitam. Nutr. Res. 2010, 80, 416. [CrossRef] [PubMed]

39. ClinicalTrials.gov: A service of the U.S. National Institutes of Health. Available online: https://clinicaltrials. gov/ (accessed on 9 June 2016).

40. Young, S. Craving Earth: Understanding Pica, the Urge to Eat Clay, Starch, Ice, and Chalk; Columbia University Press: New York, NY, USA, 2011.

41. Tako, E.; Ferket, P.; Uni, Z. Changes in chicken intestinal zinc exporter mRNA expression and small intestinal functionality following intra-amniotic zinc-methionine administration. J. Nutr. Biochem. 2005, 16, 339-346. [CrossRef] [PubMed]

42. Mete, A.; Zeeland, Y.; Vaandrager, A. Partial purification and characterization of ferritin from the liver and intestinal mucosa of chickens, turtledoves and mynahs. Avian Pathol. 2005, 34, 430-434. [CrossRef] [PubMed]

43. Passaniti, A.; Roth, T. Purification of chicken liver ferritin by two novel methods and structural comparison with horse spleen ferritin. Biochem. J. 1989, 258, 413-419. [CrossRef] [PubMed]

44. Leong, L.; Tan, B.; Ho, K. A specific stain for the detection of nonheme iron proteins in polyacrylamide gels. Anal. Biochem. 1992, 207, 317-320. [CrossRef]

45. Sheng, G.; Johnston, C.; Teppen, B. Adsorption of dinitrophenol herbicides from water by montmorillonites. Clays Clay Miner. 2002, 50, 25-34. [CrossRef]

46. Johns, T.; Duquette, M. Detoxification and mineral supplementation as functions of geophagy. Am. J. Clin. Nutr. 1991, 53, 448-456. [PubMed]

47. Fioramonti, J.; Fargeas, M.; Bueno, L. Action of T-2 toxin on gastrointestinal transit in mice: Protective effect of an argillaceous compound. Toxicol. Lett. 1987, 36, 227-232. [CrossRef]

48. Phillips, T.; Afriyie-Gyawu, E.; Williams, J. Reducing human exposure to aflatoxin through the use of clay: A review. Food Addit. Contam. 2008, 25, 134-145. [CrossRef] [PubMed]

49. More, J.; Benazet, F.; Fioramonti, J. Effects of treatment with smectite on gastric and intestinal glycoproteins in the rat: A histochemical study. Histochem. J. 1987, 19, 665-670. [CrossRef] [PubMed]

(C) 2016 by the authors; licensee MDPI, Basel, Switzerland. This article is an open access article distributed under the terms and conditions of the Creative Commons Attribution (CC-BY) license (http:/ / creativecommons.org/licenses/by/4.0/). 